\title{
Immunosuppression for interstitial lung disease in systemic sclerosis
}

\author{
Susanna Cappelli, Serena Guiducci, Silvia Bellando Randone and \\ Marco Matucci Cerinic
}

Affiliations: Dept of Biomedicine, Division of Rheumatology, University of Florence, DENOthe Center, Florence, Italy.

Correspondence: M. Matucci Cerinic, Dept of Biomedicine, Division of Rheumatology, University of Florence, Viale Pieraccini 18, 50139 Florence, Italy. E-mail: marco.matuccicerinicluunifi.it

ABSTRACT The efficacy of immunosuppressors in the treatment of systemic sclerosis-interstitial lung disease is still matter of controversy. In this review we will analyse the evidence that immunosuppressors, despite not being able to reverse fibrotic changes, may help in slowing disease progression. Induction treatment with cyclophosphamide should be started as soon as possible in patients at risk for progression. Mycophenolate mofetil and rituximab have to be considered in patients who are unable to tolerate cyclophosphamide. After remission, maintenance treatment with mycophenolate mofetil or azathioprine should be started in order to preserve the benefits achieved during the induction treatment.

○ @ERSpublications

SSc-ILD therapy consists of induction treatment and maintenance with mycophenolate mofetil or azathioprine http://ow.ly/mPsdi

\section{Introduction}

Systemic sclerosis (SSc) is characterised by obliterative microvasculopathy, activation of the immune system, and fibrosis of the skin and internal organs. In SSc, pulmonary involvement is common and comprises interstitial lung diseases (ILD) and pulmonary vascular disease leading to pulmonary arterial hypertension (PAH). A recent European League Against Rheumatism Scleroderma Trial and Research (EUSTAR) analysis revealed, in a cohort of $3656 \mathrm{SSc}$ patients, that ILD was present in $53 \%$ of cases with diffuse cutaneous (dc)SSc and in 35\% of cases with limited cutaneous SSc [1]. ILD and pulmonary hypertension are considered to be the two main causes of death in SSc. A recent report estimated lung involvement mortality to be $\sim 33 \%$ [2] and ILD to account for $16 \%$ of the deaths [3]. In total, $\sim 12 \%$ of patients with ILD develop severe, chronic respiratory failure [4]. Usually, the decline in lung function occurs in the first 4 years of disease, highlighting the importance of identifying patients at risk of ILD progression in order to treat them more aggressively to stop disease evolution. The pathogenesis of SSc-ILD is characterised by significant accumulation of inflammatory cells in the lung parenchyma both in nonspecific interstitial pneumonia (NSIP) and in usual interstitial pneumonia (UIP) followed by myofibroblast activation and collagen deposition. Therefore, immunosuppression has been hypothesised to be a useful treatment for SSc-ILD to achieve and maintain remission. The main aim of induction treatment is to block disease progression and, when possible, to reverse disease-related tissue modifications. After remission, maintenance treatment is needed to preserve the benefits obtained in the induction phase and prevent relapses.

Received: March 302013 | Accepted after revision: May 032013

Conflict of interest: Disclosures can be found alongside the online version of this article at err.ersjournals.com

Provenance: Publication of this peer-reviewed article was supported by the World Scleroderma Foundation, Switzerland (principal sponsor, European Respiratory Review issue 129).

Copyright @ERS 2013 


\section{Nonselective immunosuppressors in SSC-ILD \\ Cyclophosphamide}

Cyclophoshamide (CYC) is the most widely used and studied treatment for early and severe SSc-ILD. The use of CYC in SSc-ILD was evaluated in two randomised controlled trials (RCT) versus placebo. In the Scleroderma Lung Study I (SLS I), 158 subjects who had had SSc-ILD for $<7$ years and who had not previously received CYC were randomised to receive either oral CYC (1-2 mg $\cdot \mathrm{kg}^{-1}$ daily) for 1 year or placebo. The mean absolute difference in adjusted 12-month forced vital capacity (FVC) \% predicted between the CYC and placebo group was $2.53 \%$ (95\% CI 0.28-4.79\%) favouring CYC ( $\mathrm{p}<0.03)$ [5]. CYC treatment also resulted in alleviating breathing difficulties and improved patients' quality of life [5]. The beneficial effects of CYC persisted or increased for some months after therapy was stopped but were no longer apparent after 12 months. This evidence strongly suggests the need for maintenance treatment after CYC [6]. In the Fibrosing Alveolitis in Scleroderma Trial (FAST), 45 SSc-ILD patients were randomised to receive either 6-monthly infusions of CYC followed by 6 months of daily azathioprine (AZA) or placebo. Due to the small size of the patient cohort statistical significance was not reached. However, the adjusted between-group difference in FVC of $4.2 \%$ showed a strong trend in favour of the treated group (95\% CI 0.57-8.95, $\mathrm{p}=0.08$ ) [7]. A randomised unblinded trial comparing daily oral CYC to AZA for 18 months showed a trend toward FVC improvement in patients treated with CYC $(+3.3 \%)$ while patients receiving AZA showed a significant decrease of FVC $(-11.1 \%, \mathrm{p}<0.001)$ [8]. A meta-analysis of these three RCTs and of six prospective observational studies concluded that though an overall improvement in pulmonary function was observed in SSc patients treated with CYC this was not clinically relevant [9]. Despite this conclusion, the results previously obtained supported the use of CYC in the induction treatment of SScILD. However in the risk/benefit assessment CYC, as all the other alkylating agents, may have a significant toxicity (bone marrow suppression, teratogeneity, gonadal failure or haemorrhagic cystitis). In the SLS I, patients on CYC exhibited a significantly higher number of adverse events in comparison to patients receiving placebo [5]. It is important to note that in these studies, due to the limited follow-up, it was impossible to detect potential long-term consequences.

EUSTAR recommendations concluded that in view of high-quality RCTs (SLS and FAST), CYC should be considered for the treatment of SSc-ILD with a warning about its toxicity [10]. CYC may be administered either intravenously or orally but the use of intermittent i.v. pulses is preferred because it is less toxic [11]. There is no consensus between SSc experts about the dose of each pulse (which may range from 0.5 to $2 \mathrm{~g} \cdot \mathrm{m}^{-2}$ ) or about the duration of the therapy with CYC (generally 6-18 months).

\section{Mycophenolate mofetil}

Mycophenolate mofetil (MMF) is an antiproliferative immunosuppressive agent with a more favourable safety profile than CYC. MMF is administered orally at a dose of $2 \mathrm{~g}$ daily. At present, only observational studies on the use of MMF in SSc-ILD have been published. Due to the limited number of patients included, most of these studies did not show any significant changes of FVC or of diffusing capacity of the lung for carbon monoxide (DLCO) [12-17]. In one study, a significant increase of both FVC and DLCO was reported. In this study, patients received three consecutive daily i.v. methylprednisolone pulses before MMF, followed by five additional monthly i.v. methylprednisolone pulses and low-dose $\left(5-10 \mathrm{mg} \cdot \mathrm{day}^{-1}\right)$ oral prednisolone [18]. Therefore, it is not possible to define if the benefit observed was due to MMF or rather to the concomitant therapy with steroids. Two retrospective analyses showed a significant increase in FVC and vital capacity (VC) but no changes in DLCO [19, 20]. In a prospective study, MMF was associated with a significant increase of DLCO with a trend toward an increase in FVC [21]. In a recent study evaluating the effects of MMF on connective tissue diseases (CTD)-ILD, patients were divided into two groups; with or without UIP-pattern. MMF significantly improved FVC and DLCO in the subgroup without UIP pattern and was associated with stability of both FVC and DLCO in patients with UIP pattern [22]. A survey conducted between SSc experts has shown that MMF is only used occasionally in the induction treatment of SSc-ILD, but is the most commonly used immunosuppressor in maintenance therapy [23]. Considering the minor toxicity of MMF in comparison to CYC, many physicians have been asking themselves if MMF may be an alternative therapy to CYC as a first-line agent. The answer to this question will be given in the coming years by the ongoing Scleroderma Lung Study II (SLS II), whose aim is to compare MMF with CYC as induction treatment for SSc-ILD.

\section{Other nonselective immunosuppressors}

Azathioprine

AZA versus CYC was evaluated in a RCT in which a significant worsening of both $\operatorname{DLCO}(-11.6, \mathrm{p}<0.001)$ and FVC $(-11.1, \mathrm{p}<0.001)$ was observed after 18 months in SSc-ILD patients on AZA but not in patients on CYC [8]. Therefore, AZA may not be recommended as induction treatment in SSc-ILD. However, data 
suggested a role for AZA as maintenance treatment following i.v. CYC. A retrospective series of 27 patients with SSc-ILD showed stabilisation or improvement of lung function with a combination regimen of monthly CYC pulses administered for 6 months followed by 18 months of AZA [24]. A similar result was obtained in a prospective open-label study in which 13 patients were treated with i.v. CYC for 1 year followed by AZA for 1 year [25].

\section{Methotrexate}

Two RCTs have evaluated the use of methotrexate (MTX) in SSc [26, 27]. In these studies, while a benefit on skin involvement was described, there was no improvement in lung function. For this reason EUSTAR recommended the use of MTX for skin involvement only [10].

\section{Corticosteroids}

While the use of corticosteroids alone is recommended for idiopathic pulmonary fibrosis, several warnings about the onset of scleroderma renal crisis have significantly limited their use in SSc [28-31]. However, in several works steroids have been used in combination with CYC to treat SSc-ILD. In an Italian study, patients were treated with 6-monthly pulses of CYC $\left(1000 \mathrm{mg} \cdot \mathrm{m}^{-2}\right)$ in association with prednisone $25 \mathrm{mg}$ daily for 1 month followed by prednisone $5 \mathrm{mg}$ daily for the remaining 5 months, with stabilisation of pulmonary function in most patients [32]. In a subsequent study, patients were treated with oral CYC and $25 \mathrm{mg}$ of prednisone daily for 3 months, followed by $5 \mathrm{mg}$ daily for 9 months with favourable results [33]. In the already mentioned FAST study, patients received prednisone $20 \mathrm{mg}$ on alternate days [7]. In other studies, low doses of prednisone were used in association with CYC $[6,8]$. Two studies have outlined the therapeutic effects of using a combination of CYC and methylprednisolone pulses in patients with SSc-ILD $[34,35]$. In the first study a statistically significant improvement in the high-resolution computed tomography (HRCT) scan was observed while DLCO remained stable [34]. In the second, nearly $70 \%$ of patients showed stabilisation or improvement of pulmonary function [35]. In both studies a deterioration of lung function was observed after the end of the therapy.

\section{Biological immunotherapies \\ Rituximab}

Rituximab (RTX) is a chimeric monoclonal antibody directed against CD20, an antigen on the surface of B lymphocytes [36]. Since elevated levels of B lymphocytes have been described in the lung of patients with SSc-ILD, there is a strong rational for the use of RTX [37]. The beneficial effects of RTX on SSc-ILD have been documented in three case reports [38-40]. Some small, open-label clinical studies have explored the potential clinical efficacy of RTX in SSc. Two studies have evaluated the effects of two pulses of RTX; $1000 \mathrm{mg}$ at baseline and after 15 days $[41,42] .6$ months after RTX infusion, the pulmonary function test (PFT) remained stable [41, 42]. Recently, an open-label, randomised controlled, 1-year pilot study was conducted on 14 SSc-ILD patients. Eight patients received two cycles of RTX (baseline and 24 weeks). Each cycle consisted of four weekly RTX infusions at $375 \mathrm{mg} \cdot \mathrm{m}^{-2} \cdot \mathrm{week}^{-1}$. While the other six patients continued their previously administered treatment unchanged (prednisone alone $n=2$, CYC alone $n=1$, CYC and prednisone $\mathrm{n}=1$, and $\mathrm{MMF}$ and prednisone $\mathrm{n}=2$ ). After 1 year a significant improvement of pulmonary function (FVC: $7.5 \%, p=0.0018$; DLCO: 9.75\%, $\mathrm{p}=0.017$ ) was observed in patients treated with RTX [43]. These eight patients then received another two cycles, at an interval of 6 months. A significant improvement of pulmonary function was also observed after 2 years (FVC: 9\%, p<0.0001, DLCO: 10.88\%, p<0.001) [44]. In an open label uncontrolled study, nine patients, unresponsive to previous treatment with CYC, received one course of RTX (consisting of two infusions $1 \mathrm{~g}$ each) and PFTs remained stable through the study [45]. In all these studies RTX was always well tolerated. Encouraging results have also been reported in a retrospective study on eight patients with very severe CTD-ILD treated with RTX. Indeed a median significant improvement of FVC and DLCO was registered [46]. Since no RCT has been performed to date, the role of RTX in SSc-ILD still remains to be determined.

\section{Other biological immunotherapies}

Antitumour necrosis factor- $\alpha$, abatacept and tocilizumab

Observational studies failed to demonstrate an efficacy of antitumour necrosis factor- $\alpha$ in SSc-ILD [47, 48]. Recently a EUSTAR observational study on 27 patients with SSc-associated polyarthritis and myopathy showed no significant changes in lung fibrosis [49].

\section{Haematopoietic stem cell transplantation}

Haematopoietic stem cell transplantation (HSCT) proceeded by high CYC immunosuppressive conditioning doses has been proposed for the treatment of early dcSSc. This procedure consists of intensive immunosuppression to ablate immune responses involved in disease activity, followed by the 
infusion of haematopoietic progenitors (using CD34 selection) [50]. The aim of HSCT is to generate a new, non-autoreactive immune system. To ablate the immune response both a non-myeloablative (CYC with or without antithymocyte globulin) and a myeloablative regimen (CYC with total body irradiation or busulfan) have been proposed [51]. The joint committee of the European Group for Blood and Marrow Transplantation and the European League Against Rheumatism (EBMT/EULAR) have collected the data of 41 patients affected either by early diffuse SSc with high risk of progression or by limited SSc with threatening pulmonary fibrosis or pulmonary hypertension. Despite a remarkable improvement of skin involvement after HSCT (improvement of modified Rodnan skin score (mRss) of $>25 \%$ in $69 \%$ of patients), no positive effect on pulmonary function was recorded [52]. Values of VC and transfer factor of the lung for carbon monoxide (TLCO) were used to evaluate pulmonary function and a change in $\mathrm{VC}$ or TLCO of $>15 \%$ was considered to be clinically significant. Using this criterion in patients with lung involvement at baseline, the VC improved in $16 \%$, deteriorated in $24 \%$ and remained stable in $68 \%$ and TLCO improved in 9\%, deteriorated in 39\% and remained stable in 52\%. A high mortality rate related to the transplantation was reported (17\%) [52]. The subsequent report of EBMT/EULAR, which included an additional 25 SSc patients, confirmed a significant reduction of mRss and no significant improvement neither in VC or in TLCO. In this study, the transplantation-related mortality was reduced to $8.7 \%$ [53]. A pilot, phase II, single arm study conducted in the USA on 34 patients showed also a significant reduction of mRSS while pulmonary function was not modified. The mean increase in FVC between baseline and final evaluation was $2.11 \%(\mathrm{p}=0.50)$ while DLCO decreased by an average of $6.04 \%(\mathrm{p}=0.05)$. Treatment-related mortality was high (23\%) [54]. At present, two multicentre RCTs of CYC versus HSCT are ongoing: Autologous Stem Cell Transplantation in Scleroderma (ASTIS) in Europe and Scleroderma Cyclophosphamide or Transplant (SCOT) in the USA. Preliminary results of ASTIS show a 100-day treatment-related mortality of $10 \%$ in the transplantation arm, while the total number of deaths was higher in the control arm (24 (31.2\%) out of 77), where the majority of deaths were due to SSc progression, than in the transplant arm (16 (20.2\%) out of 79) [55].

\section{Outcome measures in evaluating the response to the treatment}

PFTs are a key outcome measure to evaluate the response to treatment. DLCO is an early marker of both ILD and PAH and correlates with disease severity [56]. Fibrotic changes result in a restrictive pattern characterised by reduced total lung capacity (TLC) and FVC. TLC is therefore a useful measure in evaluating the severity of ILD, even if most studies only consider FVC [54]. In the very early inflammatory phases of SSc-ILD, a reduction of DLCO alone is observed and is followed with ILD progression by a reduction in FVC that corresponds to the development of fibrosis. This explains the difficulty of obtaining a significant improvement of FVC through immunosuppressive therapy. In the early inflammatory phase, DLCO is more sensitive not only to interstitial but also to vascular changes.

HRCT is very useful for the diagnosis of ILD but ILD modifications may fail to change after treatment since most are due to fibrosis and therefore are irreversible. Ground-glass opacities (GGO) appear to be reversible only in a minority of patients [57], as they often represent fibrosis more than inflammation. This conclusion is in agreement with the observation that reversible inflammatory disease is found during biopsy in $<25 \%$ of SSc patients [58], despite the high frequency of GGOs on HRCT.

At present no biomarkers are validated to evaluate the efficacy of a therapeutic regimen. However, it has been observed that serum levels of surfactant protein-D and Krebs von den Lungen-6, produced by type II alveolar epithelial cells, are elevated in sera of patients with ILD [59]. In the future, a comparison of the levels before and after immunosuppressive treatment in patients with clinical improvement may define whether they could be considered as a marker of response sensitive enough to change.

It has been shown that the presence/absence of active alveolitis at bronchoalveolar lavage (BAL) did not independently predict disease progression or response to CYC at 1 year [60,61]. Therefore, the routine performance of BAL is not necessary and not helpful in RCTs.

Since breathlessness is the main symptom in patients with ILD the subjective evaluation of dyspnoea through the Mahler Dyspnoea Index may also be used to evaluate the response to the treatment [62].

Therefore, to monitor the response to treatment it is advised to consider both HRCT and PFTs. A subjective evaluation of dyspnoea by the patient may also be useful.

\section{Which patients should be treated and when?}

At present no treatment is able to solve the problem of SSc-ILD. Several studies have shown that immunosuppression slows and sometimes prevents disease progression. A physician should make their clinical profile in front of SSc-ILD patients, which include stage, activity and severity of the disease, in order to design the most appropriate treatment. Indeed, of paramount importance is to understand whether the 
disease will progress in the future. Demographic variables, in particular male sex, black race and seropositivity for antitopoisomerase I antibodies, have been associated with SSc-ILD progression [63-66]. Early disease [4], low baseline FVC and DLCO [58, 67] and a severe HRCT score at baseline [68] have also been described as predictors of progressive SSc-ILD. As for the histopatological pattern, in 80 patients with biopsy proven SSc-ILD 5-year survival was not significantly different between patients with NSIP (91\%) and UIP $(82 \%)$ [58].

Recently, an algorithm based on combined evaluation of HRCT and PFTs has been proposed to differentiate patients with extensive lung disease from those with limited lung disease. Patients with $>30 \%$ HRCT abnormalities were considered with extensive lung disease and those with $<10 \%$ with limited lung disease. In the case of HRCT extent between 10-30\% (indeterminate cases), patients were considered to be affected by extensive lung disease if the FVC was $<70 \%$ and by limited lung disease if the FVC was $<70 \%$. Patients with extensive lung disease had strikingly higher mortality and rapid deterioration of lung function [69].

When starting immunosuppressive treatment we should not only consider which patients have a higher risk of disease progression but also which have a higher probability to respond to the treatment, since variables that predict progression may be different from those that predict treatment response. At present, little is known about predictors of treatment response in SSc-ILD. Factors that have been described to be associated to treatment response are: early phase of disease [34, 35]; baseline FVC [70]; maximal severity of reticular infiltrates on HRCT at baseline; and mRss at baseline [71]. Nevertheless, in different studies, factors associated with better response were not always univocal. The observation that patients with low FVC did not respond to immunosuppression could be explained by the fact that FVC reflects disease damage rather than disease activity [70]. On the contrary, another study observed a better response to CYC in patients with more severe reticular infiltrates on HRCT [71]. Therefore, in the absence of certain factors that may tell us which patient will respond better to treatment, immunosuppression should be started as soon as possible. This should be always the strategy, especially in patients at risk of progression and with a worsening of lung function in the previous months.

\section{Conclusions}

The efficacy of immunosuppression in SSc-ILD is still a matter of debate as it is not effective in reversing fibrosis but may slow and sometimes stop disease progression. For this reason, all patients at risk of ILD progression should be treated with CYC (fig. 1). In patients who are not tolerant to CYC or in young females, induction therapy with MMF or RTX may be considered. In the presence of both ILD and severe skin involvement the possibility to perform HSCT should be discussed with the patient. If a patient does not respond to CYC, the use of RTX or of HSCT may be considered. It has been observed that lung function

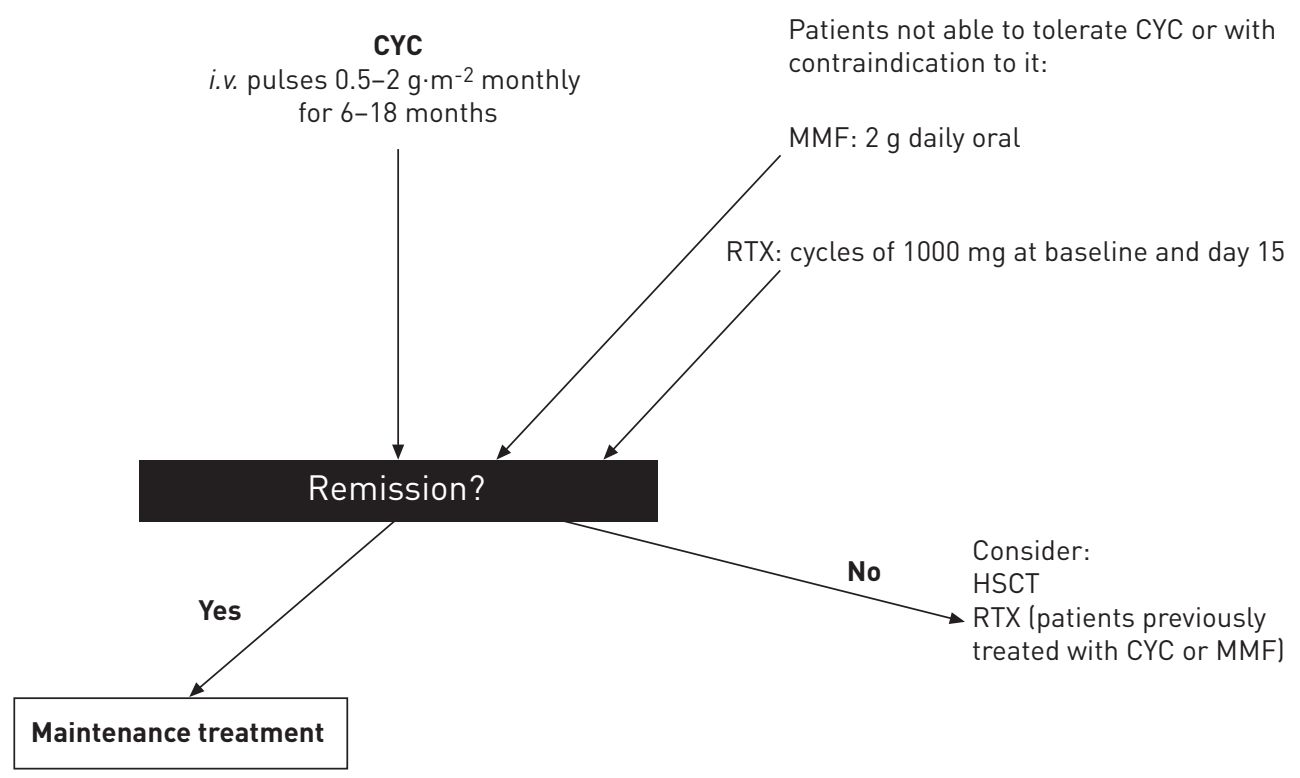

MMF: $2 \mathrm{~g}$ daily oral AZA: 1-2 $\mathrm{mg} \cdot \mathrm{kg}^{-1}$ daily oral

FIGURE 1 Algorithm for the treatment of systemic sclerosis-interstitial lung disease in patients with progressive or extensive disease. CYC: cyclophosphamide; MMF: mycophenolate mofetil; RTX: rituximab; HSCT: haematopoietic stem cell transplantation; AZA: azathioprine. 
worsens 6 months after the end of CYC therapy [6] and, therefore, after the initial induction to achieve remission maintenance treatment with MMF or AZA should be started.

Further studies on mediators and pathways of lung fibrosis are needed in order to develop new targeted therapies and improve the prognosis of patients.

\section{References}

1 Walker UA, Tyndall A, Czirják L, et al. Clinical risk assessment of organ manifestations in systemic sclerosis: a report from the EULAR Scleroderma Trials And Research group database. Ann Rheum Dis 2007; 66: 754-763.

2 Ferri C, Valentini G, Cozzi F, et al. Systemic Sclerosis Study Group of the Italian Society of Rheumatology (SIRGSSSc). Medicine (Baltimore) 2002; 81: 139-153.

3 Wells AU, Cullinan P, Hansell DM, et al. Fibrosing alveolitis associated with systemic sclerosis has a better prognosis than lone cryptogenic fibrosing alveolitis. Am J Respir Crit Care Med 1994; 149: 1583-1590.

4 Steen VD, Conte C, Owens GR, et al. Severe restrictive lung disease in systemic sclerosis. Arthritis Rheum 1994; 37 : $1283-1289$.

5 Tashkin DP, Elashoff R, Clements PJ, et al. Cyclophosphamide versus placebo in scleroderma lung disease. N Engl J Med 2006; 354: 2655-2666.

6 Tashkin DP, Elashoff R, Clements PJ, et al. Effects of 1-year treatment with cyclophosphamide on outcomes at 2 years in scleroderma lung disease. Am J Resp Crit Care Med 2007; 76: 1026-1034.

7 Hoyles RK, Ellis RW, Wellsbury J, et al. A multicenter, prospective, randomized, double-blind, placebo-controlled trial of corticosteroids and intravenous cyclophosphamide followed by oral azathioprine for the treatment of pulmonary fibrosis in scleroderma. Arhtritis Rheum 2006; 54: 3962-3970.

8 Nadashkevich O, Davis P, Fritzler M, et al. A randomized unblinded trial of cyclophosphamide versus azathioprine in the treatment of systemic sclerosis. Clin Rheum 2006; 25: 205-212.

9 Nannini C, West CP, Erwin PJ, et al. Effects of cyclophosphamide on pulmonary function in patients with scleroderma and interstitial lung disease: a systematic review and meta-analysis of randomized controlled trials and observational prospective cohort studies. Arhtritis Res Ther 2008; 10: R124.

10 Avouac J, Kowal-Bielecka O, Landewé R, et al. European League Against Rheumatism (EULAR) Scleroderma Trials and Research group (EUSTAR) recommendations for the treatment of systemic sclerosis: methods of elaboration and results of systemic literature research. Ann Rheum Dis 2009; 68: 620-628.

11 Guillevin L, Cordier JF, Lhote F, et al. A prospective, multicenter, randomized trial comparing steroids and pulse cyclophosphamide versus steroids and oral cyclophosphamide in the treatment of generalized Wegener's granulomatosis. Arthritis Rheum 1997; 40: 2187-2198.

12 Derk CT, Grace E, Shenin M, et al. A prospective open-label study of mycophenolate mofetil for the treatment of diffuse systemic sclerosis. Rheumatology 2009; 48: 1595-1599.

13 Le EN, Wigely FM, Shah AA, et al. Long-term experience of mycophenolate mofetil for treatment of diffuse cutaneous systemic sclerosis. Ann Rheum Dis 2011; 70: 1104-1107.

14 Nihtyanova SI, Brough GM, Black CM, et al. Mycophenolate mofetil in diffuse cutaneous systemic sclerosis - a retrospective analysis. Rheumatology 2007; 46: 442-445.

15 Zamora AC, Wolters PJ, Collard HR, et al. Use of mycophenolate mofetil to treat scleroderma-associated interstitial lung disease. Resp Med 2008; 102: 150-155.

16 Simeón-Aznar CP, Fonollosa-Plá V, Tolosa-Vilella C, et al. Effect of mycophenolate sodium in scleroderma-related interstitial lung disease. Clin Rheumatol 2011; 30: 1393-1398.

17 Henes JC, Horger M, Amberger C, et al. Enteric-coated mycophenolate sodium for progressive systemic sclerosis a prospective open-label study with CT histography for monitoring of fibrosis. Clin Rheumatol 2013; 32: 673-678.

18 Vanthuyne M, Blockmans D, Westhovens R, et al. A pilot study of mycophenolate mofetil combined to intravenous methylprednisolone pulses and oral low-dose glucocorticoids in severe early systemic sclerosis. Clin Exp Rheumatol 2007; 25: 287-292.

19 Koutroumpas A, Ziogas A, Alexiou, et al. Mycophenolate mofetil in systemic sclerosis-associated interstitial lung disease. Clin Rheumatol 2010; 29: 1167-1168.

20 Gerbino AJ, Goss CH, Molitor JA. Effect of mycophenolate mofetil on pulmonary function in Sclerodermaassociated interstitial lung disease. Chest 2008; 133: 455-460.

21 Liossis SNC, Bounas A, Anonopoulos AP. Mycophenolate mofetil as first-line treatment improves clinically evident early scleroderma lung disease. Rheumatology 2006; 45: 1005-1008.

22 Fischer A, Brown KK, Du Bois RM, et al. Mycophenolate mofetil improves lung function in connective tissue disease-associated interstitial lung disease. J Rheumatol 2013; 40: 640-646.

23 Walker KM, Pope J. Treatment of systemic sclerosis complications: what to use when first-line treatment fails - a consensus of systemic sclerosis experts. Semin Arthritis Rheum 2012; 42: 42-55.

24 Bérezné A, Ranque B, Valeyre D, et al. Therapeutic strategy combining intravenous cyclophosphamide followed by oral azathioprine to treat worsening interstitial lung disease associated with systemic sclerosis: a retrospective multicenter open-label study. J Rheumatol 2008; 35: 1064-1072.

25 Paone C, Chiarolanza I, Cuomo G, et al. Twelve-month azathioprine as maintenance therapy in early diffuse systemic sclerosis patients treated for 1-year with low dose cyclophosphamide pulse therapy. Clin Exp Rheumatol 2007; 25: 613-616.

26 Van den Hoogen FH, Boerbooms AM, Swaak AJ, et al. Comparison of methotrexate with placebo in the treatment of systemic sclerosis: a 24 week randomized double-blind trial, followed by a 24 week observational trial. $\mathrm{Br} J$ Rheumatol 1996; 35: 364-372.

27 Pope JE, Bellamy N, Seibold JR, et al. A randomized, controlled trial of methotrexate versus placebo in early diffuse scleroderma. Arthritis Rheum 2001; 44: 1351-1358.

28 Steen VD, Medsger TA Jr. Case-control study of corticosteroids and other drugs that either precipitate or protect from the development of scleroderma renal crisis. Arthritis Rheum 1998; 41: 1613-1619.

29 Teixeira L, Mouthon L, Mahr A, et al. Group Français de Recherche sur le Sclérodermie (GFRS). Mortality and risk factors of scleroderma renal crisis: a French retrospective study of 50 patients.. Ann Rheum Dis 2008; 67: 110-116. 
versus low-dose of penillamine in early diffuse systomic sclerosis tral. Arthritis Rheum 2002; 46: 298 , versus low-dose of penicillamine in early diffuse systemic sclerosis trial. Arthritis Rheum 2002; 46: $2983-2989$.

31 Helfrich DJ, Banner B, Steen VD, et al. Normotensive renal failure in systemic sclerosis. Arthritis Rheum 1989; 32: 1128-1134.

32 Giacomelli R, Valentini G, Salsano F, et al. Cyclophosphamide pulse regimen in the treatment of alveolitis in systemic sclerosis. J Rheumatol 2002; 29: 731-736.

33 Beretta L, Caronni M, Raimondi M, et al. Oral cyclophosphamide improves pulmonary function in scleroderma patients with fibrosing alveolitis: experience in one centre. Clin Rheumatol 2007; 26: 168-172.

34 Griffiths B, Miles S, Moss H, et al. Systemic sclerosis and interstitial lung disease: a pilot study using pulse intravenous methylprednisolone and cyclophosphamide to assess the effect on high resolution computed tomography scan and lung function. J Rheumatol 2002; 29: 2371-2378.

35 Yiannopoulos G, Pastromas V, Antonopoulos I, et al. Combination of intravenous pulses of cyclophosphamide and methylprednisolone in patients with systemic sclerosis and interstitial lung disease. Rheumatol Int 2007; 27: 357-361. Manno R, Boin F. Immunotherapy of systemic sclerosis. Immunotherapy 2010; 2: 863-878.

37 Lafyatis R, O'Hara C, Feghali-Bostwick CA, et al. B cell infiltration in systemic sclerosis-associated interstitial lung disease. Arthritis Rheum 2007; 56: 3167-3168.

38 McGonagle D, Tan AL, Madden J, et al. Successful treatment of resistant scleroderma-associated interstitial lung disease with rituximab. Rheumatology 2008; 47: 552-553.

39 Daoussis D, Liossis SN, Tsamandas AC, et al. Is there a role for B-cell depletion as therapy for scleroderma? A case report and review of the literature. Semin Arthritis Rheum 2010; 40: 127-136.

40 Yoo WH. Successful treatment of steroid and cyclophosphamide-resistant diffuse scleroderma-associated interstitial lung disease with rituximab. Rheumatol Int 2012; 32: 795-798.

41 Smith V, Van Praet JT, Vandooren B, et al. Rituximab in diffuse cutaneous systemic sclerosis: an open label clinical and histopatological study. Ann Rheum Dis 2010; 69: 193-197.

42 Layaftis R, Kissin E, York M, et al. B cell depletion with rituximab in patients with diffuse cutaneous systemic sclerosis. Arthritis Rheum 2009; 60: 578-583.

43 Daoussis D, Liossis SN, Tsamandas AC, et al. Experience with rituximab in scleroderma: results from a 1-year, proof-of-principle study. Rheumatology 2010; 49: 271-280.

44 Daoussis D, Liossis SN, Tsmandas AC, et al. Effect of long-term treatment with rituximab on pulmonary function and skin fibrosis in patients with diffuse systemic sclerosis. Clin Exp Rheum 2012; 30: 17-22.

45 Bosello S, De Santis M, Lama G, et al. B cell depletion in diffuse progressive systemic sclerosis: safety, skin score modification and IL-6 modulation in an up to thirty-six months follow-up open-label trial. Arthritis Res Ther 2010; 12: R54.

46 Keir GJ, Maher TM, Hansell DM, et al. Severe interstitial lung disease in connective tissue disease: rituximab as rescue therapy. Eur Respir J 2012; 40: 641-648.

47 Lam GK, Hummers LK, Woods A, et al. Efficacy and safety of etanercept in the treatment of scleroderma-associated joint disease. J Rheumatol 2007; 34: 1636-1637.

48 Denton CP, Engelhart M, Tvede N, et al. An open-label pilot study of infliximab therapy in diffuse cutaneous systemic sclerosis. Ann Rheum Dis 2009; 68: 1433-1439.

49 Elhai M, Meunier M, Matucci-Cerinic M, et al. Outcomes of patients with systemic sclerosis-associated polyarthritis and myopathy treated with tocilizumab or abatacept: a EUSTAR observational study. Ann Rheum Dis 2012; 72: 1217-1220.

50 Khanna D, Denton CP. Evidence-based management of rapidly progressing systemic sclerosis. Best Pract Res Clin Rheumatol 2010; 24: 387-400.

51 Tyndall A, Matucci-Cerinic M. Haematopoietic stem cell transplantation for the treatment of systemic sclerosis and other autoimmune disorders. Expert Opin Biol Ther 2003; 3: 1041-1049.

52 Binks M, Passweg JR, Furst D, et al. Phase I/II trial of autologous stem cell transplantation in systemic sclerosis: procedure related mortality and impact on skin disease. Ann Rheum Dis 2001; 60: 577-584.

53 Farge D, Passweg J, van Laar JM, et al. Autologous stem cell transplantation in the treatment of systemic sclerosis: report from the EBMT/EULAR Registry. Ann Rheum Dis 2004; 63: 974-981.

54 Nash RA, McSweeney PA, Crofford LJ, et al. High-dose immunosuppressive therapy and autologous hematopoietic cell transplantation for severe systemic sclerosis: long-term follow-up of the US multicenter pilot study. Blood 2007; 110: 1388-1396.

55 Van Laar JM, Farge D, Sont JK, et al. The ASTIS trial: autologous stem cell transplantation versus IV pulse cyclophosphamide in poor prognosis systemic sclerosis, first results. Ann Rheum Dis 2012; 71: 151.

56 Wells AU, Steen V, Valentini G. Pulmonary complications: one of the most challenging complications of systemic sclerosis. Rheumatology 2009; 48: iii40-iii44.

57 Shah RM, Jimenez S, Wechsler R. Significance of ground-glass opacity on HRCT in long-term follow-up of patients with systemic sclerosis. J Thorac Imaging 2007; 22: 120-124.

58 Bouros D, Wells AU, Nicholson AG, et al. Histopathologic subsets of fibrosing alveolitis in patients with systemic sclerosis and their relationship to outcome. Am J Respir Crit Care Med 2002; 165: 1581-1586.

59 Yanaba K, Hasegawa M, Takehara K, et al. Comparative study of serum surfactant protein-D and KL-6 concentrations in patients with systemic sclerosis as markers for monitoring the activity of pulmonary fibrosis. J Rheumatol 2004; 31: 1112-1120.

60 Strange C, Bolster MB, Roth MD, et al. Bronchoalveolar lavage and response to cyclophosphamide in scleroderma interstitial lung disease. Am J Respir Crit Care Med 2008; 177: 91-98.

61 Wells AU. The clinical utility of bronchoalveolar lavage in diffuse parenchymal lung disease. Eur Respir Rev 2010; 19: 237-241.

62 Mahler DA, Weinberg DH, Wells CK, et al. The measurement of dyspnea. Contents, interobserver agreement, and physiologic correlates of two new clinical indexes. Chest 1984; 85: 751-758.

63 Barnett AJ. Scleroderma (progressive systemic sclerosis) progress and course based on a personal series of 118 cases. Med J Aust 1978; 2: 129-134.

64 Steen VD, Owens GR, Redmond C, et al. The effect of D-penicillamine on pulmonary findings in systemic sclerosis. Arthritis Rheum 1985; 28: 882-888. 
Greidinger EL, Flaherty KT, White B, et al. African-American race and antibodies to topoisomerase I are associated with increased severity of scleroderma lung disease. Chest 1998; 114: 801-807.

66 Assassi S, Sharif R, Lasky RE, et al. Predictors of interstitial lung disease in early systemic sclerosis: a prospective longitudinal study of the GENISOS cohort. Arthritis Res Ther 2010; 12: R166.

67 Plastiras SC, Karadimitrakis SP, Ziakas PD, et al. Scleroderma lung: initial forced vital capacity as predictor of pulmonary function decline. Arthritis Rheum 2006; 55: 598-602.

68 Khanna D, Tseng CH, Farmani N, et al. Clinical course of lung physiology in patients with scleroderma and interstitial lung disease. Arthritis Rheum 2011; 63: 3078-3085.

69 Goh NS, Desai SR, Veeraraghavan S, et al. Interstitial lung disease in systemic sclerosis: a simple staging system. Am J Respir Crit Care Med 2008; 177: 1248-1254.

70 Hudson M, Steele R, Canadian Scleroderma Research Group, et al. Immunosuppression for interstitial lung disease in systemic sclerosis - novel insights and opportunities for translational research. J Cell Commun Signal 2012; 6: 187-190.

71 Roth MD, Tseng CH, Clements PJ, et al. Predicting treatment outcomes and responder subsets in sclerodermarelated interstitial lung disease. Arthritis Rheum 2011; 63: 2797-2808. 